\title{
OS MECANISMOS DE CONTROLE DA INFLAÇÃO E A POSSIBILIDADE DE USO DO CADE ${ }^{1}$
}

\author{
THE MECHANISMS OF CONTROL INFLATION AND THE POSSIBILITY OF \\ USE OF CADE
}

\author{
Daniel Francisco Nagao Menezes \\ Universidade Presbiteriana Mackenzie - Campinas - São Paulo - Brasil \\ Rafael Quaresma Viva \\ Universidade Presbiteriana Mackenzie - Campinas - São Paulo - Brasil
}

\begin{abstract}
RESUMO: A pretensão do artigo é demonstra a possibilidade de uso do CADE (Conselho Administrativo de Defesa Econômica) como mecanismo de combate à inflação. Argumenta-se que o CADE está vinculado a um sistema estatal de intervenção na ordem econômica, sistema este em que, cada organismo, não atua isoladamente em suas funções institucionais, mas sim, deve buscar o equilíbrio sistêmico de toda a ordem econômica. Por tais razões, - CADE não deve permanecer exclusivamente na sua missão institucional de combater a concentração econômica mas sim, ser utilizada como ferramenta de combate à inflação.
\end{abstract}

PALAVRAS CHAVE: Controle da Inflação, CADE, Concorrência; Intervenção Estatal; Políticas Públicas.

ABSTRACT: The intention of the article is demonstrating the possibility of using the CADE (Administrative Council for Economic Defense) as a mechanism to combat inflation. It is argued that CADE is linked to a system of state intervention in the economic order, a system in which every body does not act alone in its institutional functions, but rather should seek the systemic balance of the entire economic order. For these reasons, CADE should not remain exclusively in its institutional mission to combat the economic concentration but rather be used as a tool to fight inflation.

KEYWORDS: Inflation Control, CADE, Competition, State Intervention; Public Policy.

\footnotetext{
${ }^{1}$ Artigo decorrente do projeto A Faceta Anti-inflacionária do CADE, financiado pelo CNPQ.
} 


\section{INTRODUÇÃO}

A inflação é tema permanente nas discussões econômicas brasileiras desde o Império. Tanto na Primeira República, com as tentativas de controle inflacionário nas ações de Rui Barbosa com a chamada Crise do Encilhamento², passando pelo chamado período Getuliano, que vai de 1930 até 1964, bem como do período militar até os dias presentes, a inflação é algo que ronda a história econômica brasileira.

Os números da inflação impressionam e, apesar das tentativas de estabilizá-la, este nunca esteve sob total controle estatal. A título de exemplo, durante a década de oitenta, auge do processo inflacionário, a inflação salta de 415,83\% em 1987, para 2.708,55\% ao ano em 1993, ano em que o Cruzeiro passa a se chamar Cruzeiro Real. A moeda vigora até 30 de junho de 1994, quando é substituída pela unidade de real de valor (URV), o indexador da nova moeda, o Real, equivalia na época a 2.700 cruzeiros reais. Em 1ํ de julho de 1994 entra em vigor o Plano Real. A nova moeda consegue dominar a inflação, a um custo social altíssimo, sem congelar preços, sem confisco de depósitos bancários e de outros artifícios semelhantes. Quatro anos depois, a inflação chega a 3,12\%, a menor taxa verificada no País desde novembro de 1949 após décadas ininterruptas de inflação de dois dígitos.

Todas as tentativas históricas de controle da inflação, inclusive o Plano Real, decorrem de políticas econômicas denominadas monetaristas, as quais tem por pensamento central a ideia que a estabilidade da economia decorre da utilização de instrumentos exclusivamente monetários, tais como controle de volume de moeda em circulação e, controle dos meios de pagamento. As teorias monetaristas por sua vez, não se sustentam mais na atual conjuntura

\footnotetext{
2 A Crise do Encilhamento foi uma bolha econômica que ocorreu no Brasil, entre o final da Monarquia e início da República, estourando durante o governo provisório de Deodoro da Fonseca (1889-1891), tendo em decorrência se transformado numa crise financeira. Os então respectivos Ministros da Fazenda Visconde de Ouro Preto e Rui Barbosa, sob a justificativa de estimular a industrialização no País, adotaram uma política baseada em créditos livres aos investimentos industriais garantidos por farta emissão monetária. Pelo modo como o processo foi legalmente estruturado e gerenciado, junto com a expansão dos Capitais financeiro e industrial, vieram desenfreadas especulação financeira em todos os mercados e forte alta inflacionária causadas pelo desconfiança oriunda de determinadas práticas no mercado financeiro, como excesso de lançamento de ações sem lastro.
} 
econômica $^{3}$ e, desde a década de 50 e 60 já vem sendo criticada no meio acadêmico, principalmente no âmbito das discussões da CEPAL ${ }^{4}$.

Com isto, temos que, hoje, as posições estruturalistas predominam sobre as monetaristas e, nesta vertente, será analisado o tema que o artigo se propõe a debater, qual seja, as consequências das decisões do CADE sobre o controle inflacionário.

\section{OS TIPOS DE INFLAÇÃO E SUAS CONSEQUÊNCIAS}

\section{Antes de adentrarmos nas consequências das decisões do CADE sobre o} controle da inflação, devemos entender melhor os tipos e causas da inflação. Nos valemos, da lição de $\operatorname{SICSÚ}^{5}$ (2003, p. 14) para quem existem sete tipos de inflação:

\footnotetext{
${ }^{3}$ Em 1983, na palestra intitulada Money, Credit and Banking realizada nos encontros da Western Economic Association, nos Estados Unidos, o Prêmio Nobel de Economia, James TOBIN (1996, p. 471) afirma: "um grande número de arquitetos monetários está pronto para preencher esse vácuo". O vácuo aberto pela derrocada monetarista, para Tobin, foi preenchido pelo estabelecimento de uma nova regra que deve disciplinar a política monetária e buscar manter a inflação sob controle.

4 "Na última metade do século passado, houve dois debates com abordagens não-convencionais sobre o tema inflação. Um deles ocorreu nos anos 1950-60 e foi patrocinado pela abordagem estruturalista pertencente aos economistas ligados à Cepal. Simultaneamente, principalmente nos Estados Unidos, desenvolvia-se o debate sobre a inflação de demanda (demand-pull) e a inflação de custos (cost-push). Uma segunda rodada de discussões sobre o tema se deu nos anos 1980, com o debate sobre os choques heterodoxos e a abordagem inercialista. Esta última é bastante importante diante de processos inflacionários agudos e crônicos, enquanto aquele debate que ocorreu nos anos 1950-1960 e muito mais proveitoso para situações de baixa inflação - e é para esta última situação que o artigo pretende contribuir. A abordagem estruturalista dos anos 1950-1960 afirmava que as políticas contracionistas não eram capazes de combater a inflação. A expansão monetária não era considerada a causa da inflação, mas sim as imperfeições estruturais. A moeda se expandia não como causa da inflação, mas como resultado de uma elevação generalizada dos preços nas economias latino-americanas. Os estruturalistas defendiam a idéia de que o crescimento gerava déficits externos que causavam pressões de demanda no mercado de divisas e, em conseqüência, provocavam uma desvalorização cambial elevando os custos que eram repassados aos preços. A inflação era, portanto, um subproduto do crescimento nos países latino-americanos, assim como os déficits externos eram também um subproduto do crescimento. A abordagem estruturalista é iam método de análise, é muito mais do que o diagnóstico das causas específicas da inflação latinoamericana nos anos 1950-1960." (SICSÚ, 2003, p. 07)

5 "Inflação de salários- Os aumentos salariais são obtidos nas negociações entre trabalhadores e empresários. Um aumento dos salários nominais, cet. par, causará inflação. Este evento é normalmente chamado de inflação de salários. Quando o hiato de emprego é reduzido, é mais fácil para os trabalhadores individualmente ou coletivamente obterem tais ganhos e é mais fácil para os empresários repassarem essa elevação de custos aos preços. Sendo assim, esse tipo de inflação tende a se tomar mais perigoso quando o hiato de emprego diminui. Um aumento de salário não causará inflação se for compensado por um aumento da produtividade-. Tal aumento, por seu turno, não guarda qualquer relação com o tamanho do hiato de emprego. A
} 
capacidade dos aumentos de produtividade de manter (ou reduzir) os preços depende das barganhas entre empresários e trabalhadores, isto é, dependerá de quanto dos ganhos de produtividade se transformam em aumento de margem de lucro ou de salários. A produtividade, por sua vez, depende em grande medida da adoção de políticas de desenvolvimento tecnológico e qualificação de trabalhadores por parte do governo e por parte das empresas. A inflação de salários pode ocorrer também com um hiato de emprego mais elevado, desde que um grupo significativo de trabalhadores consiga (por qualquer motivo, por exemplo, por possuir habilidades diferenciadas) obter ganhos salariais e, ainda, que os empresários não sofrem pressões de demanda relevantes no seu mercado no momento da passagem dessa elevação de custos para os preços. Em outras palavras, é necessário que a indústria, em que houve o aumento de salários, tenha um elevado grau de monopólio. Contudo, tais situações são mais raras, e o mais comum é que a redução do hiato de emprego tenda a aumentar as chances da inflação de salários ocorrer - já que é sob tais condições que os empresários têm mais liberdade para aumentar preços. Inflação de grau de monopólio ou inflação de lucros - Quando os empresários percebem que a demanda em seus mercados possui uma elasticidade favorável à elevação das suas margens de lucro provocam uma elevação de preços. Tal inflação foi chamada por Davidson (1994, p. 144) de inflação de grau de monopólio ou inflação de lucros. Lavoie (1992) classificou tal tipo como inflação dc preços administrados Não existe nenhuma justificativa teórica que estabeleça que as mudanças no nível de mark-up estão necessariamente associadas ao tamanho do hiato de emprego. Isto implica que há autores que acreditam que as margens de lucro aumentam quando a economia está em fase de crescimento, como R. Harrod, e há autores que acreditam exatamente no contrário, como M.Kalecki (Davidson, 1994, p. 144). O potencial da inflação de lucros depende diretamente do grau de monopólio da economia. Inflação de retornos decrescentes- A inflação de retornos decrescentes, tal como chamada por Davidson (1994, p. 143), é relevante porque esse tipo de retornos está normalmente presente na economia sob certas condições. Em verdade, as firmas operam com retornos constantes para uma faixa muito extensa do hiato de emprego. Portanto, não é qualquer redução do hiato de emprego que provocará escassez de insumos necessários à produção ou escassez de trabalhadores qualificados. As firmas buscam proteção, por exemplo, estocando insumos (ou working capital on goods-in-process). Entretanto, uma redução do hiato de emprego, quando este já é baixo, faz com que a economia adentre a faixa de retornos decrescentes. Acredita-se que, quando o hiato de emprego é muito baixo, o capital toma-se mais eficiente que o trabalho (Davidson, 1994, p. 143). Nestas condições, são contratados trabalhadores menos qualificados que utilizam o capital de última geração de forma menos eficiente. As firmas não têm como se proteger da escassez de mão-de-obra qualificada. Segundo Keynes, essa é a principal razão da inflação quando a economia está em situação próxima ao pleno emprego. Portanto, este tipo de inflação somente assume importância quando o hiato de emprego é muito baixo e sofre alguma redução. Inflação importada - Uma economia pode ter inflação importada do exterior. A capacidade do exterior de influenciar a trajetória de preços domésticos dependerá da variação do nível de preços internacional e da variação do valor taxa de câmbio. Quanto maior o grau de abertura da economia, maior será a inflação importada potencial. Define-se o grau de abertura de uma economia, tal como Davidson (1994,p. 204), como sendo a razão total de gastos com importações/total de gastos domésticos com produtos c serviços finais (ambos, numerador e denominador, medidos na moeda doméstica). Um grau de abertura maior gera maior inflação importada potencial, porque quanto mais produtos são comprados no exterior em relação ao total de produtos adquiridos pelos residentes, maior é a probabilidade de um aumento de um produto qualquer internacional influenciar o nível de preços domésticos. Então, quanto maior o grau de abertura da economia, maior será o número de produtos importados que compõem a cesta doméstica de cálculo da inflação. Se a taxa de câmbio permanece constante, mas houve um aumento em dólares de produtos importados que compõem a cesta de compras domésticas, cet.par., haverá inflação. $\mathrm{O}$ mesmo ocorre se os preços dessas mercadorias não se alteram em dólares, mas há uma desvalorização da moeda doméstica em relação ao dólar. Em ambos os casos há aumento de preços na moeda doméstica. O potencial da inflação importada pode ser explicado também pelo hiato de emprego e pelo grau de monopólio da economia. Uma elevação de preços (na moeda nacional) de produtos importados, seja devido a uma variação cambial seja em virtude de um aumento de preços em dólares, representa um custo para as empresas que utilizam ou comercializam tais produtos na economia doméstica. Como qualquer outro 
(i) inflação de salários,

(ii) inflação de lucros,

(iii) inflação e rendimentos decrescentes,

(iv) inflação importada,

(v) choques inflacionários,

(vi) inflação de impostos e,

(vii) inflação de demanda.

A maioria dos economistas relaciona por sua vez, o tipo da inflação, com o mecanismo de combate a inflação, em uma verdadeira relação causa-efeito (PEREIRA, NAKANO, 1984, p. 105). Já para SANDRONI (2003, p.301):

independentemente da causa inicial do processo de elevação dos preços, a inflação adquire autonomia suficiente para se auto-alimentar por meio de reações em cadeia.

As consequências causadas pela inflação no âmbito econômico-social, geralmente prejudicam certas classes de pessoas enquanto beneficiam outras. ROSSETTI (1988, p.217) afirma que:

custo, são mais facilmente repassados aos preços quando o hiato de emprego é baixo ou quando o grau de monopólio (do setor atingido pelo problema externo) é elevado. Choques de oferta inflacionários- Consideram-se choques inflacionários somente aqueles choques domésticos de oferta que podem provocar um aumento de custos. Davidson (1994, p. 158) chamou a inflação decorrente de tais choques de inflação spoton inflação de commodity. Os choques de oferta tendem a causar aumentos de custos, como exemplos podem ser citados a quebra de uma safra agrícola ou a escassez de energia elétrica. Como todos os outros aumentos de custos apontados anteriormente, os aumentos de custos advindos de choques de oferta domésticos serão mais facilmente repassados aos preços quando o hiato de emprego for menor. Se o hiato de emprego não é reduzido, mas o setor atingido possui elevado grau de monopólio, os custos serão repassados aos preços, cet.par., causando inflação. Logo, o potencial da inflação de commodity depende do hiato de emprego e do grau de monopólio da economia. Quando o hiato de emprego é elevado e o grau de monopólio é baixo, um choque negativo de oferta pode causar somente compressão de margens de lucro.

Inflação de impostos- Os impostos são determinados pelo governo central. Quando a alíquota de impostos é alterada, cet.par, há um impacto direto sobre o nível de preços. A alíquota de tributação é determinada com base nas necessidades de gastos públicos. O aumento de alíquotas, cet.par., tende a ter um impacto maior sobre os preços quando os empresários podem repassar o aumento de custos tributários aos preços, e tal liberdade é maior quanto menor é o hiato de emprego. Portanto, o potencial da inflação causada por um choque tributário será maior quanto menor for o tamanho do hiato de emprego e maior o grau de monopólio da economia. Os aumentos de alíquotas podem também causar um efeito considerável sobre o nível de preços, mesmo quando o hiato de emprego não for baixo, bastando que o aumento de alíquota incida sobre os produtos que sejam negociados em mercados com elevado grau de monopólio (em que os empresários repassam facilmente uma elevação de custos aos preços). Inflação de demanda - A inflação de demanda ocorre quando o hiato de emprego não é mais positivo. Neste estágio, os aumentos de gastos do governo, de investimento ou de consumo provocam inflação, cet. par.. Sendo assim, a inflação de demanda potencial tende a se elevar quando o hiato de emprego é zero. Uma vez alcançado o pleno emprego, novos trabalhadores somente aceitarão trabalhar por um salário real mais elevado (adotando-se, é óbvio, a hipótese de que não há mudanças nas preferências trabalho-lazer). Para haver aumento de salários reais, nessas condições, necessariamente terá que haver um aumento de salários nominais e um aumento de preços. Caso o primeiro tenha um aumento superior ao segundo, pode-se dizer que, pelo menos inicialmente, haverá em situação de inflação de demanda uma compressão percentual das margens de lucro, embora o volume total de lucros seja maior." (SICSÚ, 2003, p. 10) 
a redução do poder aquisitivo da moeda atingirá, sobretudo os que vivem de rendimentos temporariamente fixos, como assalariados [...]", aposentados e pensionistas, cujos rendimentos são corroídos diariamente pela inflação, por aqueles que recebem rendas variáveis e ajustáveis às alterações dos preços, como empresários, trabalhadores autônomos e profissionais liberais, provocando ou realimentando a inflação.

Outras consequências, por exemplo, sobre o mercado de crédito, os investimentos produtivos, balanço de pagamentos internacional, também são relevantes. Afirma ROSSETTI (1988, p.219) que: "O impacto dessas consequências tem caracterizado a inflação como um dos mais graves problemas econômicos das nações".

Entretanto, mais de cinco décadas de elevada inflação no Brasil - entre meados dos anos 50 e o início do novo século - trouxeram poucas lições. Por essa razão é que as "medidas contra a inflação" sempre deixaram de lado as origens do problema ${ }^{6}$. Descontrolada, a inflação corrói salários, principalmente do trabalhador de menor renda, que não consegue investir e proteger o poder de compra do dinheiro.

Portanto, observa-se que combater a inflação em um país de economia instável, sensível às oscilações do mercado interno e externo, como o Brasil, torna-se difícil, pois as determinantes da inflação são as mais diversas possíveis e influenciam a economia como um todo.

Em países, como o nosso, nos quais a inflação é uma constante ameaça à economia, é endêmica, perene e estrutural. A compreensão da efetividade dos mecanismos não-monetários de controle é medida necessária para o desenvolvimento do país e controle inflacionário uma vez que, medidas isoladas como as tomadas até a presente data não surtiram efeitos ou, os efeitos colaterais são maiores que os ganhos efetivos.

Neste sentido, assim como nas Constituições Brasileiras anteriores à 1988, há no Brasil a previsão da existência de um sistema complexo de

\footnotetext{
${ }^{6}$ Apesar de todo o avanço da ciência econômica, o principal mecanismo de controle da inflação é a chamada taxa de juros básica (Selic), quando ela sobe, cai o volume de dinheiro em circulação no país, pois aumenta o interesse das pessoas em poupar e receber os juros pagos pelas aplicações financeiras. Ao mesmo tempo a procura por empréstimos fica menor e os preços tendem a baixar com o pouco consumo, com isso a inflação perde força. Outras formas de manter a inflação sob domínio são a política cambial (relação entre o dólar ou outras moedas estrangeiras) e uma política econômica capaz de atrair investimentos externos, entre outros. Em linhas gerais, o principal mecanismo, continua a ser um instrumento monetarista.
} 
proteção à concorrência como quesito fundamental da ordem econômica adotada pelo país.

\section{DA DEFESA DA CONCORRÊNCIA COMO INSTRUMENTO DE COMBATE À INFLAÇÃO}

Até meados do século XIX não existiam indícios de regulamentação do mercado em relação às atividades econômicas, que eram exercidas livremente sob a influência dos padrões liberais, fundamentados principalmente na ideia de mercado auto regulável, sem a intervenção do Estado. A primeira tentativa de regulação e limitação do mercado econômico foi o Act for the Prevention and Supression of Combinations Formed in Restraint of Trade, criado em 1889 no Canadá. No entanto, a normativa que influenciou de maneira geral as legislações nacionais sobre a concorrência foi o Sherman Antitrust Act, criada em 1890, nos Estados Unidos (AGUILLAR, 2006, p. 224).

A citada legislação norte-americana tem como objetivo o controle e regulação do mercado, impedindo a formação de trustes e atribuindo punições à atuação dos mesmos, considerando como essenciais a garantia de liberdade de iniciativa econômica para todos os empreendimentos. Observa-se no texto do Sherman Act a preocupação do Estado em estabelecer um impedimento para a criação de monopólios, proibindo todo e qualquer contrato ou combinação, não apenas organizado como truste, consideradas também como ilegais as combinações restritivas formadas entre Estados.

O modelo norte-americano por sua vez influenciou a legislação brasileira que, desde Getúlio Vargas, passou a estruturar um modelo de intervenção do Estado na economia de forma a tentar controlar a inflação. Por tal razão o modelo interventivo na ordem econômica aparece na Constituição de 1934 e, cria uma estrutura infra constitucional de controle econômico, estrutura que levou posteriormente à criação do CADE.

O Brasil efetiva com a Constituição Federal de 1988 um modelo de intervenção do Estado no Domínio Econômico que permite uma gama de ações estatais para controle de uma série de questões econômicas. Dentre essas várias possibilidades que vão deste o monopólio estatal até o simples 
monitoramento de índices econômicos, encontramos a Defesa da Concorrência que, a partir de 1988 é tratada como Princípio da Ordem Econômica pelo art. 170, V da Constituição Federal que criar um equilíbrio entre livre iniciativa e proteção ao trabalho humano, valendo trazer aqui as lições de Tércio Sampaio FERRAZ JÚNIOR(1989, p. 50):

Nestes termos, o art. 170, ao proclamar a livre iniciativa e a valorização
do trabalho humano como fundamentos da ordem econômica está
nelas reconhecendo a sua base, aquilo sobre o que ela se constrói, ao
mesmo tempo sua conditio per quam e conditio sine qua non, os
fatores sem os quais a ordem reconhecida deixa de sê-lo, passa a ser
outra, diferente, constitucionalmente inaceitável. Particularmente a
afirmação da livre iniciativa, que mais de perto nos interessa neste
passo, ao ser estabelecida como fundamento, aponta para uma ordem
econômica reconhecida então como contingente. Afirmar a livre
iniciativa como base é reconhecer na liberdade um dos fatores
estruturais da ordem, é afirmar a autonomia empreendedora do
homem na conformação da atividade econômica, aceitando a sua
intrínseca contingência e fragilidade; é preferir, assim, uma ordem
aberta ao fracasso a uma 'estabilidade' supostamente certa e eficiente.
Afirma-se, pois, que a estrutura da ordem está centrada na atividade
das pessoas e dos grupos e não na atividade do Estado. Isto não
significa, porém, uma ordem do 'laissez faire', posto que a livre
iniciativa se conjuga com a valorização do trabalho humano, mas a
liberdade, como fundamento, pertence a ambos. Na iniciativa, em
termos de liberdade negativa, da ausência de impedimentos e da
expansão da própria criatividade. Na valorização do trabalho humano,
em termos de liberdade positiva, de participação sem alienações na
construção da riqueza econômica. Não há, pois, propriamente, um
sentido absoluto e ilimitado na livre iniciativa, que por isso não exclui a
atividade normativa e reguladora do Estado. Mas há ilimitação no
sentido de principiar a atividade econômica, de espontaneidade
humana na produção de algo novo, de começar algo que não estava
antes. Esta espontaneidade, base da produção da riqueza, é o fator
estrutural que não pode ser negado pelo Estado. Se, ao fazê-lo, o
Estado a bloqueia e impede, não está intervindo, no sentido de normar
e regular, mas está dirigindo e, com isso, substituindo-se a ela na
estrutura fundamental do mercado.

No âmbito infraconstitucional é criado o SBDC - Sistema Brasileiro de Defesa da Concorrência, cuja missão fundamental é a manutenção da competição entre os agentes econômicos no modelo econômico brasileiro. $\mathrm{O}$ SBDC, por sua vez, é formado pela Secretaria de Direito Econômico (SDE), vinculado ao Ministério da Justiça; pela Secretaria de Acompanhamento Econômico (Seae), vinculado ao Ministério da Fazenda; e pelo Conselho Administrativo de Defesa Econômica (CADE), autarquia federal vinculada ao Ministério da Justiça. 
Atualmente, não só o CADE, mas todo o SBDC, é regido pela lei 12.529 de 30 de novembro de 2011, que por sua vez, tem a missão de controlar todo o sistema econômico e não só a concorrência.

O CADE, por integrar uma sistema complexo, o SBDC, não pode e não deve atuar de forma exclusiva na defesa da concorrência, como defendem muitos autores de viés mais liberal. A sua natureza estrutural é instrumental, ou seja, o CADE é um meio de exercício da política (ordem) econômica prevista no art. 170 da Constituição Federal. Como já demonstrado acima, todos os princípios da ordem econômicos compõem um todo, sendo impossível a atuação isolada de um deles.

Logo, o CADE, na sua atuação como instrumento de política econômica de Estado, deve atuar pensando em todos os princípios da ordem econômico e não única e exclusivamente na defesa da concorrência, como molda a lei 12.529/11 e suas antecessoras.

Todos os instrumentos colocados pelo Estado para a efetivação dos princípios da ordem econômica somente atingem seus fins se atuarem visando a efetivação de todos os princípios da ordem econômica constitucional, como bem notou a professora Paula Andréa FORGIONI (1998, p. 170):

em um contexto de proteção da economia popular (cf. Decreto-lei 869 ,
de 1938, e Decreto-lei 7.666 , de 1945), o que, sem sombra de dúvidas,
já lhe atribui um caráter instrumental ainda que vinculado à economia
popular e ao consumidor. O caráter instrumental da proteção da
concorrência permanece na atual Constituição, que manda reprimir o
abuso do poder econômico que vise a dominação dos mercados e à
eliminação da concorrência (art. 173, §4º), em atenção ao princípio da
livre concorrência (art. 170, IV). Manda, também, reprimir o aumento
arbitrário de lucros (art. 173, §4º), conforme o princípio da defesa do
consumidor (art. 170, inc. V). Essa proteção, entretanto, vai inserta no
fim geral e maior, qual seja, "assegurar a todos existência digna,
conforme os ditames da justiça social"

No mesmo sentido temos o voto do então Ministro Eros Grau no $\mathrm{V}$. Acórdão de sua relatoria na ADI 1.950/SP:

É certo que a ordem econômica na Constituição de 1.988 define opção por um sistema, o sistema capitalista, no qual joga um papel primordial a livre iniciativa. Essa circunstância não legitima, no entanto, a assertiva de que o Estado só intervirá na economia em situações excepcionais. Muito ao contrário.

A ordem econômica ou Constituição econômica pode ser definida, enquanto parcela da ordem jurídica, mundo do dever ser, como o sistema de normas que define, institucionalmente, determinado modo de produção econômica. A ordem econômica diretiva contemplada na 
Constituição de 1.988 propõe a transformação do mundo do ser. Diz o seu art. 170 que a ordem econômica [mundo do ser] deverá estar fundada na valorização do trabalho e na livre iniciativa e deverá ter por fim assegurar a todos a existência digna, conforme os ditames da justiça social, observados determinados princípios. É a Constituição diretiva. Mais do que simples instrumento de governo, a nossa Constituição enuncia diretrizes, programas e fins a serem realizados pelo Estado e pela sociedade. Postula um plano de ação global normativo para o Estado e a sociedade, informado pelos preceitos veiculados pelos seus artigos $1^{\circ}, 3^{\circ}$ e 170 . Os fundamentos e os fins definidos em seus artigos $1^{\circ}$ e $3^{\circ}$ são os fundamentos e os fins da sociedade brasileira.

Como bem ponderou Eros Grau em seu voto, a atuação do Estado na economia se dá por uma ação global ${ }^{7}$, isto é, em todas as frentes, motivo pelo qual, não pode o $\mathrm{CADE}$, limitar-se a atuar somente no controle da concorrência como prevê a lei 12.529/11. O CADE, ao analisar uma conduta prevista na lei 12.529/11 deveria não somente se ater a defesa da concorrência, mas a todos os efeitos da ação analisada na ordem econômica, posição diferente do seu leading case (Processo Administrativo 08012.006516/2001-20)

\section{DA AMPLIAÇÃO DAS COMPETÊNCIAS DO CADE COM A LEI $12.529 / 11$}

O que estamos tentando demonstrar é que a Constituição Federal de 1988 traz um modelo de intervenção na economia que ocorre de várias formas. Legalmente, a atuação do Estado na economia é tratada na própria Constituição Federal em seus art. 173 e seguintes. Em linhas gerais o art. 173 da CF garante a iniciativa econômica privada exceto nos casos de relevante interesse nacional ou necessário à segurança nacional, fazendo ressalva aqui aos monopólios da união previstos no art. 177 da Constituição. Já no art. 174, o Estado chama para

\footnotetext{
${ }^{7}$ Devemos trazer o pensamento de Magali KLAJMIC (1998, p. 86) "O texto legal, ao adotar o princípio do abuso, consagrou, também, a regra da razão, condicionando a caracterização do ilícito à configuração dos efeitos, potenciais ou efetivos, alcançados ou não, de prejudicar a livre concorrência ou a livre iniciativa, dominar mercado relevante de bens ou serviços, aumentar arbitrariamente os lucros ou exercer de forma abusiva posição dominante. Extraiu-se o conceito da Jurisprudência americana, que incorporou o entendimento da Suprema Corte no caso Standard Oil Co. of New Jersey vs. United States, em 1911, no sentido de que "a pretensão da Lei Sherman não é de restringir o direito de celebrar e fazer cumprir contratos, mas sim de proteger o comércio de restrições não razoáveis." Significa, na prática, que as condutas devem ser examinadas à luz da conjuntura econômica em que se inserem para a verificação de sua razoabilidade e proporcionalidade. Como se vê, a Lei n.. $8.884 / 94$, ao contrário das leis norteamericanas, não acolhe o sistema de enquadramento dos ilícitos per se, isto é, aquelas práticas que por si só caracterizam-se como abusivas para a norma legal."
} 
si o papel de agente regulador e normatizador da atividade econômica, fazendo isso através das funções de fiscalização, incentivo e planejamento econômico.

Disso concluímos que a presença do Estado no Domínio Econômico se dá de quatro formas ${ }^{8}$ : a) institucional; b) normativa ou reguladora; c) participativa e d) interventiva.

Assim, defendemos que a atuação de todos os instrumentos do Estado (órgãos estatais) são voltados para estas quatro formas de intervenção econômica de forma concomitante. Logo, a atuação do CADE, não poderia ser diferente, devendo a autarquia federal atuar em todo o contexto econômico que, por sua vez está previsto na Constituição Federal (art. 170 e seguintes).

Além disso, os instrumentos de Estado devem atuar de forma coordenada no alcance dos princípios econômicos, evitando-se a segmentação da atuação dos entes estatais. Economia, Direito e Política caminham de forma correlata que podemos afirmar que o texto jurídico da Constituição traz um programa econômico estruturado na forma de decisão política fundamental. Neste sentido, temos Gilberto BERCOVICI (2011, p. 209):

A constituição econômica contemporânea é uma constituição econômica diretiva, ou seja, dotada de um programa de política econômica. Não é possível separar a constituição econômica da constituição do Estado. Só há uma constituição, que é de toda a comunidade política. A ordem jurídica da economia, para Horst Ehmke, tem que ser compreendida como a ordem de toda a coletividade, não de parcela desta.

Neste sentido é que deve ser interpretado o art. 9º, II da Lei 12.529/11:

Art. 9ำ Compete ao Plenário do Tribunal, dentre outras atribuições previstas nesta Lei:

II - decidir sobre a existência de infração à ordem econômica e aplicar as penalidades previstas em lei;

\footnotetext{
${ }^{8}$ No tocante as formas, este se dividem em duas - diretas e indiretas. Fazemos remissão às lições de João Bosco Leopoldino da Fonseca: "Como visto, as formas ou modalidades pelas quais o Estado inervem no setor econômico são diversos e cada um deles pode assumir as mais amplas estruturas. Vimos que o Estado pode atuar diretamente no domínio econômico, e pode atuar só indiretamente. No primeiro caso, assume a forma de empresa pública, nome genérico que compreende no sistema jurídico brasileiro as empresas públicas propriamente ditas e as sociedades de economia mista, assim mencionadas no art. 173, §§ $1^{\circ}$, $2^{\circ}$ e e $3^{\circ}$ da Constituição Federal. No segundo caso, atuação indireta, o Estado o faz através de normas que tem como finalidade fiscalizar, incentivar ou planejar; o planejamento, como se verá é somente indicativo para o setor privado. Esta forma de atuação do Estado está prevista no art. 174 da Constituição Federal." FONSECA (2005, p. 280)
} 
A interpretação a ser data ao inciso II do art. 9ำ da Lei 12.529/11 é ampliativa, ou seja, que o conceito de ordem econômica não é somente aquele previsto na lei ordinária (Decreto-Lei 869/38 e, Leis 8.137/90, 8.176/91), mas sim toda a ordem econômica prevista nos arts. 170 e seguintes da Constituição Federal de 1988 e também, as normas diretivas da Constituição previstas entre os artigos $1^{\circ}$ a $3^{\circ}$.

Desta forma, o CADE na sua atuação não deve se limitar a defesa da concorrência (art. 170, V da CF/88), mas atuar na defesa de todos os incisos do art. 170 e seguintes da Constituição. A atuação do CADE possui reflexos necessários e naturais nas demais características de nossa ordem econômica.

Um exemplo que podemos citar é o controle do CADE sobre a inflação inercial - isto é, aquela inflação passada repassada aos preços atuais. Quanto maior a concentração econômica, maior o poder dos agentes econômicos em repassar tais custos aos preços finais. Inexistindo concorrência entre os agentes econômicos, que é garantida pelo CADE, não há disputa entre os agentes no item "preço" podendo levar a processos inflacionários em determinados setores da economia.

Entretanto, nada impede que o CADE ao se defrontar com um ato de abuso do poder econômico, isto é, qualquer ato que seja de sua competência julgar, não deve se restringir a matéria de sua competência originária, podendo e devendo analisar as questões reflexas.

O mencionado exemplo da inflação é enriquecedor. O CADE num perspectiva consequêncialista de suas decisões deve considerar no momento do julgamento, os reflexos (consequências) sobre o controle da inflação que a decisão terá.

O CADE, em um exemplo hipotético de formação de cartel no setor farmacêutico, pode analisar se há concentração, ou mesmo concorrência desleal, a partir do abuso dos preços praticados, questão que não vem fazendo. Ou ainda, poderá o CADE na aplicação de uma medida punitiva a ato de concentração, interferir na política de preços dos agentes econômicos investigados, sem conduto, ferir competência executiva de outro órgão de fiscalização, como por exemplo, alguma agência reguladora. 


\section{CONCLUSÕES}

As pretensões do artigo são simples: demonstrar a existência de uma interconexão entre os vários instrumentos estatais que permitam não só ao $\mathrm{CADE}$, mas a todo o SBDC tomar decisões que possuam reflexos (positivos) no controle da inflação.

Existe estrutura jurídica a permitir que todos os órgãos de defesa da concorrência atuem no sentido de proteger toda a ordem econômica e não só setores específicos ou tão somente a concorrência como parece ser a tendência do órgão nas últimas décadas.

A Constituição Federal é una ${ }^{9}$ e, por tal motivo os princípios da ordem econômica somente possuem razão existencial se interpretados conjuntamente. Além do Princípio da Unidade, a Constituição possui força normativa, isto é, capacidade de alterar a realidade segundo as decisões fundamentais expressas no texto constitucional, no caso brasileiro, a estruturação de uma ordem econômica voltada para atingir os dispositivos do art. $3^{\circ}$ da Constituição Federal. Assim sendo, a ordem econômica é una e voltada para construir uma sociedade livre, justa e solidária; garantir o desenvolvimento nacional; erradicar a pobreza e a marginalização e reduzir as desigualdades sociais e regionais e; promover o bem de todos, sem preconceitos de origem, raça, sexo, cor, idade e quaisquer outras formas de discriminação.

A Ordem Econômica por sua vez, em que pese as vozes liberais contrárias de a ordem econômica é direcionada para limitar o Estado, ela é voltada para limitar a atividade econômica como um todo. Nas várias expressões da "Ordem Econômica" estão contidas as verdadeiras limitações ao

\footnotetext{
9 "O princípio da unidade da Constituição ganha relevo autônomo como princípio interpretativo quando com ele se quer significar que o Direito Constitucional deve ser interpretado de forma a evitar contradições (antinomias, antagonismos) entre as suas normas e, sobretudo, entre os princípios jurídicos-políticos constitucionalmente estruturantes. Como 'ponto de orientação', 'guia de discussão' e 'factor hermenêutico de decisão' o princípio da unidade obriga o intérprete a considerar a Constituição na sua globalidade e procurar harmonizar os espaços de tensão [...] existentes entre as normas constitucionais concretizar. Daí que o intérprete deva sempre considerar as normas constitucionais, não como normas isoladas e dispersas, mas sim como preceitos integrados num sistema interno unitário de normas e princípios a concretizar. Daí que o intérprete deva sempre considerar as normas constitucionais, não como normas isoladas e dispersas, mas sim como preceitos integrados num sistema interno unitário de normas e princípios." (CANOTILHO, 1991, p. 162)
} 
instituto jurídico da livre concorrência. A ordem econômica, no entendimento de Raul Machado HORTA (1996, p. 286), é o "conjunto de regras constitucionais reguladoras da atividade econômica". Já de acordo com João Bosco Leopoldino da FONSECA (1995, p. 86), a ordem econômica pode ser definida "como aquele conjunto de princípios estabelecidos pela Constituição e que tem por objetivo fixar os parâmetros da atividade econômica, coordenando a atuação dos diversos sujeitos que põem em prática aquela mesma atividade". Assinala o mesmo autor que ao conjunto daqueles princípios costuma-se dar o nome de "constituição econômica", salientando estar a mesma intrinsecamente ligada à "constituição política", formando, com esta última, uma unidade indissociável

A leitura do art. $9^{\circ}$ da Lei 12.529/11, em especial do termo "ordem econômica" se feito com base no Princípio da Máxima Eficiência da Constituição, permite com que seja entendido que o CADE poderá atuar em todos os aspectos da estrutura econômica do país a partir do controle da concorrência.

Isto é, se a partir do controle da concorrência o CADE encontrar a necessidade de atuar sobre outro pilar da ordem econômica que não o do inciso V do art. 170 da Constituição Federal, poderá fazê-lo, não devendo restringir sua atuação.

Neste sentido, o art. 170, V da CF, embora regulamentado pelo legislador ordinário, precisa de constante revisão para ampliar a atuação do Estado na Ordem Econômica.

Propomos com isso a criação de uma nova modalidade de norma constitucional, a que necessita de regulamentação permanente, como é o caso do art. 170, V da CF que não basta ser regulamentado mas sim, constantemente aprimorado.

\section{REFERÊNCIAS BIBLIOGRÁFICAS}

AGUILLAR, Fernando Herren. Direito Econômico - do direito nacional ao direito supranacional. São Paulo: Atlas, 2006.

BERCOVICI, Gilberto. Direito Econômico do Petróleo e dos Recursos Naturais. São Paulo: Quartier Latin. 2011. 
BRASIL. Constituição da República Federativa do Brasil de 05 e outubro de 1988.

BRASIL. Decreto-Lei 869 de 18 de novembro de 1934.

BRASIL. Lei Federal 8.137 de 27 de dezembro de 1990.

BRASIL. Lei Federal 8.176 de 8 de fevereiro de 1991.

BRASIL. Lei Federal 12.529 de 30 de novembro de 2011.

BRASIL. Supremo Tribunal Federal. Ação Direta de Inconstitucionalidade 1.950/SP.

CANOTILHO, Joaquim José Gomes. Direito Constitucional. 5 ed. Coimbra: Almedina, 1991.

FERRAZ JÚNIOR, Tércio Sampaio. A economia e o controle do Estado, parecer publicado no jornal "O Estado de S. Paulo", p. 50, em 04.06.1989, apud GRAU, Eros Roberto. A Ordem Econômica na Constituição de 1988. 5ª ed., São Paulo: Malheiros, 2000, p. 232.

FONSECA, João Bosco Leopoldino da. Lei de proteção da concorrência. Rio de Janeiro: Forense, 1995.

FONSECA, João Bosco Leopoldino da. Direito Econômico. 5a Ed. Rio de Janeiro: Forense. 2005.

FORGIONI, Paula Andréa. Os Fundamentos do Antitruste. São Paulo: Revista dos Tribunais, 1998.

HORTA, Raul Machado Horta. Estudos de Direito constitucional. Belo Horizonte: Del Rey, 1996.

KLAJMIC, Magali. Política Legal da Concorrência. Revista de Direito Econômico do CADE. n. 27. jan/jul 1998. Brasília: Conselho Administrativo de Defesa Econômica. p. 79-94.

PEREIRA, Luiz Carlos Bresser, NAKANO, Yoshiaki. Política Administrativa de Controle da Inflação. Revista de Economia Política. Vol. 04. N. 03. Jul/set 1984. p. 105-125.

ROSSETTI, José Paschoal. Introdução à economia. 13.ed. São Paulo: Atlas, 1988.

SANDRONI, Paulo. Novíssimo dicionário de economia. 11.ed. São Paulo: Best Seller, 2003. 
SICSÚ, João. Políticas Não-Monetárias de Controle da Inflação: uma proposta pós-keynesiana. Revista Análise Econômica. Ano 21, n. 39. Porto Alegre: UFRS, 2003. p. 03-24.

TOBIN, James. Essays in Economics: National and International. Cambridge: MIT Press, 1996. 